\title{
PENSAR O GÉNERO NA PUBLICIDADE: PERCEPÇÕES DE ESTUDANTES DO ENSINO SUPERIOR PORTUGUÊS
}

\author{
Ana Reis Jorge \\ Centro Interdisciplinar em Ciências Sociais da Universidade do Minho (CICS.Nova/UMinho). Email: \\ ana.j.mr@gmail.com \\ Carla Cerqueira \\ Centro de Estudos em Comunicação e Sociedade da Universidade do Minho (CECS/UMinho). \\ Universidade Lusófona do Porto (ULP). Email: carlaprec3@gmail.com

\section{Sara I. Magalhães} \\ Centro de Psicologia da Universidade do Porto (CPUP). Email: saraisabelmagalhaes@gmail.com
}

Resumo: Neste artigo discutem-se resultados do projeto PubliDiversidade ${ }^{1}$. Após a realização de grupos focais com jovens universitárias/os da área de comunicação, analisaram-se as suas percepções relativamente à dimensão de género na publicidade, enfatizando também as estratégias de auto e heteroregulação existentes. Concluiu-se pela escassez de perspetivas críticas e de rutura face a representações genderizadas em anúncios publicitários, subtraindo-as a imperativos sociais e de mercado, embora algumas/alguns

\footnotetext{
1 O Projeto PubliDiversidade - Representações e Igualdade de Género na Publicidade, promovido pela União de Mulheres Alternativa e Resposta (UMAR), Organização Não-Governamental portuguesa com importante trabalho realizado no âmbito da promoção da Igualdade de Género, decorreu nos anos de 2013 e 2014 e foi financiado pelo Programa Operacional para o Potencial Humano. O projeto intentou promover o debate/reflexão crítica em torno da publicidade e marketing em Portugal, sensibilizando para os processos de produção e receção daquela, assumindo uma perspetiva de investigação-ação junto de jovens estudantes, profissionais das áreas e da própria sociedade civil.
}

participantes tenham apresentado discursos que remetem para alguma reflexividade. Neste sentido, o estudo aponta para a necessidade de ampliação de uma literacia publicitária crítica, com previsível impacto na edificação de uma publicidade pautada pela igualdade de género.

Palavras-chave: Publicidade. Género. Jovens. Portugal.

\begin{abstract}
The present paper discusses the results of the research project PubliDiversidade. Through focus group discussions with young Portuguese university students from communication courses, we sought to scan the main perceptions of these young students towards advertising, highlighting also existing self- and hetero-regulation strategies. We concluded for the absence of critical and rupture
\end{abstract}


perspectives with gendered representations in ads, subtracting them to social and market imperatives, although some of the participants showed some discourses that could remit to some reflectiveness. In this sense, the study shows the importance of the enlargement of critical media literacy, with predictable impact on the promotion of advertisements lined by gender equality.

Keywords: Advertisements. Gender.

Youth. Portugal.

\section{Introdução}

Nas últimas décadas,

verificaram-se inúmeros avanços em matéria de igualdade de género, nomeadamente em Portugal. Porém, importa não obscurecer as permanências, insuficiências e resistências passivas e ativas a uma realidade ainda marcada por profundas desigualdades. Se, tal como refere Silva (2008: 65), as desigualdades de género, "quer vistas numa perspectiva diacrónica, quer consideradas numa abordagem sincrónica, são ainda uma realidade atual e operante a vários níveis", é necessário promover um olhar atento e crítico face à retórica da igualdade que tende a encerrar um certo

efeito de backlash, no sentido enunciado por Faludi (1991), ao relegar as conquistas e 'escolhas' das mulheres para o plano individual.

Neste sentido, as amplas mudanças ocorridas no país - que acarretaram marcas de passado (Almeida, 2013) - não foram acompanhadas de um efetivo debate público sobre a ideologia de género, nem tão pouco de uma continuidade de políticas ativas no sentido da igualdade (Amâncio, 1994). Este facto permitenos ainda reconhecer as limitações de uma atuação fundamentalmente jurídico-formal no que toca à erradicação deste e de outros tipos de desigualdade, ademais frequentemente interligados, o que revela as potencialidades de perspetivas assentes na teoria da interseccionalidade ${ }^{2}$, a qual considera a multidimensionalidade das experiências vividas, assim como a interseção, a conivência e a mutualidade entre os diversos sistemas de opressão social.

\footnotetext{
2 Tendo por base a especificidade da situação das mulheres negras, Crenshaw releva as potencialidades da assunção da interseccionalidade enquanto conceito que procura associar as consequências estruturais e interativas da interpenetração de dois ou mais eixos de subordinação. Alerta-se, assim, para a existência cumulativa de vetores (etnia, género, classe, etc.), que condicionam a matriz de desigualdades e posições relativas no seio dos grupos, pautados por diversidade interna (Crenshaw, 2002:177).
} 
As desigualdades de género assumem geografias diversas e graus de incidência diferenciados nos vários domínios da(s) sociedade(s), pelo que importa atender à sua tendencial transversalidade. Enquanto agentes fundamentais de socialização, os média destacam-se como mecanismos discursivos e disciplinares por excelência, sendo (re)produtores de assimetrias devido ao seu inegável impacto nas mundividências e nos comportamentos de cidadãs/ãos e ao papel preponderante que desempenham na formação de opiniões públicas e na configuração de práticas de consumo.

Na esteira de Machado e Santos (2009: 8), "os media modernos, como quaisquer outras empresas orientadas para a optimização de recursos e obtenção de lucros, operam numa lógica de mercado que implica a atração de consumidores e de receitas de publicidade". Sob este entendimento não causará estranheza o alheamento dos média em relação às (des)igualdades entre homens e mulheres através, por exemplo, da disseminação de conteúdos estereotipados e da simples omissão de realidades que são, de resto, frequentemente diversas (Cerqueira, 2012).

Enquanto "técnica de comunicação de massas, destinada a um público específico e que é especialmente paga e utilizada com o objetivo de dar a conhecer e valorizar uma Marca (produto, serviço ou instituição)" (Rasquilha, 2009: 36), a publicidade constitui um território de pesquisa particularmente fecundo. Encontrando-se largamente associada às dinâmicas de mercado mas constituindo também um instrumento de consumo de massas (González et al., 1991), colabora, não raras vezes, na reificação de assimetrias de género. Nas palavras de Mota-Ribeiro (2010: 43), “o género (genre) publicitário exprime e implica, não só um conjunto de significados e valores sociais específicos, mas também determinados pressupostos acerca das subjetividades socialmente construídas dos participantes (publicitários, anunciantes, consumidores)".

É, pois, notória uma elevada permeabilidade da publicidade à veiculação e, consequentemente, sedimentação de representações estereotipadas de mulheres e homens assentes no binómio femininomasculino. Mas, se, como sustenta Hall 
(1997), os significados compartilhados social e culturalmente em diversas instituições sociais e materializados são passíveis de serem alterados, também os média - e, dentro destes, a publicidade são não só dispositivos dinâmicos, de administração e de controlo, mas também de resistência social (Esteves, 2003: 93).

Deste modo, urge uma intervenção neste domínio com vista à construção de uma efetiva igualdade entre mulheres e homens na sua diversidade. Ademais, apesar de se ter assistido nas últimas décadas à proliferação de medidas, programas e recomendações nacionais e internacionais dirigidos à integração de uma perspectiva de género na área mediática, e onde a publicidade é sublinhada (Arnaut, 2011; Cerqueira e Cabecinhas, 2012), são ainda escassos os projetos de intervenção que promovem a desmistificação de representações genderizadas/sexistas neste domínio em Portugal, mormente no âmbito da publicidade.

Para a prossecução desta investigação-ação, privilegiou-se como público-alvo as/os estudantes do ensino superior da área da comunicação, já que não só constituem potenciais futuras/os profissionais nas indústrias publicitárias, como são também recetoras/es e consumidoras/es de produtos mediáticos. Procurou-se auscultar não apenas as suas percepções face ao género na publicidade e suas implicações na perpetuação de desigualdades, como também estimular a negociação e a consequente desconstrução de estereótipos de género, estimulando condutas ativas no sentido da construção da igualdade.

Publicidade e representações de género: que rumos?

O conceito de representação social, enquanto forma de conhecimento socialmente elaborada e partilhada no sentido da construção de práticas e de uma realidade comum (Jodelet, 1989), inicialmente formulado por Moscovici (1981), tem-se configurado desde o seu surgimento como um importante aliado para a compreensão dos média como recetores e (re)produtores de "realidades". Remetendo para os papéis sociais e correlativos estereótipos, as representações sociais de género assumem centralidade neste contexto. Se é inegável que a construção de representações assume um caráter interativo, estando estas sujeitas à 
mudança, importa notar que a persistência de padrões genderizados associados a constrangimentos de ordem sociocultural, económica e simbólica concorre frequentemente para a sua relativa estabilidade no tempo (Cabecinhas, 2007; Lorenzi-Cioldi, 2002; van Dijk, 1991). Uma vez que os estereótipos $^{3}$ constituem parte das representações sociais, no que concerne ao género, estes "estão sendo claramente assumidos no consumo mediático e em especial na publicidade, como reprodutora das realidades sociais e das ideologias" (Goffman, 1979: 42), contribuindo para a sedimentação de desigualdades. É precisamente no âmbito do questionamento da publicidade enquanto reprodutora de determinadas ideologias, nomeadamente de género, que centramos este artigo.

Não obscurecendo todas as lutas empreendidas pelos movimentos de mulheres e feministas há mais de um século, é relativamente comum situar a

3 O conceito de estereótipo surge, no âmbito das Ciências Sociais, com Walter Lippmann em 1922, remetendo para a ideia de concepções mentais fixas compartilhadas no seio de um grupo. Sendo inúmeros os estudos posteriores baseados nesta premissa inicial, e conhecendo o conceito importantes desenvolvimentos, nomeadamente com Tajfel (1982), é aqui de realçar a sua inegável associação aos contextos históricos e socioculturais em que são (re)produzidos. criação da Declaração Universal dos Direitos Humanos (1948) como o primeiro contributo políticoinstitucional e estratégia concertada na arena internacional em prol da igualdade de género. Não ausente de críticas, esta não deixou de ter impacto, embora diferenciado, na definição de medidas de cariz sociopolítico e legal em diversos países.

Porém, na década de 1970, com a deliberação da Década da Mulher (1975-1985) pela Organização das Nações Unidas, a problemática das desigualdades de género e da discriminação contra as mulheres é colocada, de forma mais evidente, na agenda política de diversos Estadosmembros. Destaca-se, a este respeito, a Convenção sobre a Eliminação de Todas as Formas de Discriminação contra as Mulheres (1979) enquanto a primeira regulamentação internacional neste domínio. Além disso, no que concerne ao campo específico dos média, a Declaração e Plataforma de Ação de Pequim, adotada aquando da IV Conferência Mundial sobre as Mulheres (1995), inclui a área “As Mulheres e os Media", assumindo-a como um ponto-chave de atuação. $\mathrm{Na}$ secção $\mathrm{J}$, ressaltam-se dois objetivos 
estratégicos: i) “incrementar a participação e o acesso das mulheres à expressão das suas ideias e à tomada de decisão nos meios de comunicação social e através deles, e nas novas tecnologias da comunicação" (CIDM, 2005: 170) e ii) "fomentar uma imagem equilibrada e não estereotipada das mulheres nos meios de comunicação social" (CIDM, 2005: 173).

Mais do que a proliferação de conferências, recomendações e documentos/instrumentos internacionais, importa notar que este facto estimulou também o ativismo e a investigação científica, mormente sobre os média, suas estruturas e produtos (Gallagher, 2001). A publicidade e o marketing beneficiaram também deste movimento, merecendo crescente atenção nas últimas décadas (e.g., Cronin, 2000; Lazar, 2014).

Ainda que inúmeros instrumentos internacionais - como a Resolução sobre a discriminação da mulher na publicidade (1997), a Resolução 1557 do Conselho da Europa (2007) e a Resolução sobre a forma como marketing e a publicidade afectam a igualdade entre mulheres e homens (2008) - tenham alertado para o papel da publicidade na reificação de assimetrias de género, a questão da imagem (nomeadamente das mulheres) foi, desde cedo, objeto de atenção no seio do movimento feminista. Como refere Mota-Ribeiro, "discutir 'imagens' adquire uma importância particular, não apenas devido ao domínio e significância associados às imagens na cultura atual, mas também porque o visual é um traço particularmente marcante do feminino" (2010: 59) traduzido na secular auto e hetero-vigilância das/pelas mulheres.

Desde a segunda metade do século XX, inúmeros debates (e.g., Creedon e Cramer, 2007) têm procurado explorar a relação entre a reduzida presença das mulheres em profissões mediáticas e nas indústrias publicitárias, nomeadamente no que se refere aos cargos de chefia e à disseminação de conteúdos e de imagens sexistas. Sendo relativamente recente a entrada de mulheres em áreas como a produção, a fotografia, a edição e a realização, têm-se questionado as possibilidades de fuga à estereotipia e à discriminação, num contexto ideologizado, onde os grupos dominantes atuam no sentido de servirem os seus próprios interesses (Marshment, 1993: 126). 
Contudo, considerando que este domínio não se presta a leituras simplistas e face à atual tendência para a "feminização" das profissões mediáticas, não parece razoável assumir que estamos perante uma evidente transformação de conteúdos (Gallagher, 2001). Por exemplo, no que concerne especificamente às imagens, pese embora a presença de mulheres envolvidas na sua produção, ainda escassa em cargos de chefia, o controlo destas sobre as representações de género parece ser diminuto (MotaRibeiro, 2010). Vários estudos têm, justamente, demonstrado que as mulheres em profissões mediáticas tendem a internalizar rotinas de trabalho que reproduzem e enfatizam desigualdades de género (Creedon \& Cramer, 2007; Gallego, 2013; Ross, 2009; Subtil, 2009). Afigura-se, pois, demasiado otimista a assunção de que é generalizada entre as mulheres uma espécie de consciência de género, da mesma forma que seria demasiado pessimista e dicotomizador assumir que não existem homens comprometidos com a conquista da igualdade de género que, de resto, apresentam também inúmeras potencialidades no que toca à expressão das suas individualidades.
A representação da feminilidade, do feminino e das mulheres em imagens publicitárias tem constituído outro aspeto fundamental no âmbito da crítica feminista (MotaRibeiro, 2010). Nas últimas décadas, inúmeros estudos têm questionado a veiculação de representações essencialistas e redutoras das experiências, identidades e (inter)subjectividades (Januário, 2016). As representações não são verdadeiras ou falsas; são, ao invés, produtos de um processo ativo de seleção e de apresentação que contribui para a construção de significados (Thornham, 1998). Para esta visão tem contribuído, nomeadamente em Portugal, os trabalhos de Mota-Ribeiro (2011) na desconstrução da semiótica da imagem publicitária veiculada em Portugal.

A crítica feminista sobre a fraca representação numérica das mulheres nas imagens, nomeadamente mediáticas, associada à promoção de estereótipos baseados numa dicotomização essencializadora, através da objetificação dos corpos e da exploração dos papéis tradicionais de género, levou a que se sugerisse como estratégia a sua substituição por imagens assentes na diversidade. 
Todavia, inúmeras críticas têm sido feitas ao seu potencial emancipatório: se, por um lado, não existe uma ideia consensual quanto ao que consubstancia a realidade das mulheres, no seio do feminismo (van Zoonen, 1994); por outro, parece algo contraproducente uma abordagem desatenta à produção cultural de significados sobre $\mathbf{0}$ "feminino" e o "masculino" (Marshment, 1993), e ao próprio intuito fantasioso que permeia as imagens mediáticas. A estes argumentos somamse os perigos da produção de imagens que de tão congruentes com as realidades de opressão não confluem para a construção da paridade (e.g., situações de violência física, psicológica, social, económica e simbólica), bem como de outras de cunho positivo (e.g., mulheres profissionalmente bem sucedidas e em cargos de topo), alheias e obscurecedoras de estruturas atravessadas por múltiplas desigualdades (Betterton, 1987; Marshment, 1993; Kilbourne, 1999; Lazar, 2014).

O recente apelo publicitário às ditas novas masculinidades parece vir ainda alimentar esta discussão. Embora as suas potencialidades sejam realçadas crescentemente - não apenas ao nível da desconstrução de estereótipos de género, mas também em termos de consumo, de imagens nas quais homens assumem papéis que reportam ao privado e ao doméstico (Zawisza e Cinnirella, 2010) -, estas encontram-se ainda pouco exploradas. Porém, ao nível da sexualização, se não mesmo da objetificação dos corpos dos homens, deparamo-nos em anos recentes com a sua clara expansão. A este propósito, como referem Januário e Cascais (2012: 146), “a indústria mediática descobriu no corpo masculino uma grande potencialidade de consumo e tornou-a um forte mercado a ser explorado". Talvez ainda seja prematura uma avaliação do impacto destas novas configurações ao nível dos padrões de género, mas são já reveladoras do potencial de (re)invenção no campo publicitário e de disseminação de renovados estereótipos assentes na idealização.

A mera inversão, a substituição ou a diversificação de imagens do "ser homem" e "ser mulher", per se, parece insuficiente para uma efetiva conquista da igualdade. Esta exige, de resto, uma perspetiva intersecional e uma intervenção integrada no sentido da 
erradicação das desigualdades de género, mas também daquelas com base na etnia, na orientação sexual, na classe, na idade, entre outras. Como argumenta Silva, a erradicação das desigualdades de género - social e politicamente construídas - implica, além de uma mudança de mentalidades e o empoderamento das mulheres por via das suas próprias organizações, uma articulação com "as lutas sociais com base no critério de classe, ou melhor dito, dos interesses das classes e dos grupos sociais explorados e oprimidos" (2008: 87).

O exercício criativo, ainda que cuidadoso, de desconstruir e (re)criar imagens poderá contribuir para novas configurações de significados e caminhar no sentido da igualdade. Entende-se, pois, que urge a aposta numa literacia crítica para os média e, em concreto, para a publicidade.

\section{Educar para uma leitura crítica mediática e publicitária}

Partindo do pressuposto de que os média são produtores/produtos socioculturais, a questão do acesso informado de cidadãs/ãos aos mesmos é fundamental. Kellner e Share (2005) referem mesmo que nos inserimos numa cultura mediática na qual a importância da literacia é cada vez mais inquestionável. Materializado na capacidade de descodificar o conteúdo das mensagens veiculadas e a veicular, o acesso situa-se no domínio da urgência (Thomas e Jolls, 2004), sob pena do grosso da população se ver afastado da tomada de decisões e incapacitado de refletir, responder e desafiar criticamente uma sociedade em mutação. Kellner e Share (2007: 59) viriam a reforçar esta ideia admitindo que,

"In the 21 st century, critical
media literacy is an imperative for
participatory democracy because
new information communication
technologies and a market-based
media culture have fragmented,
connected, converged, diversified,
homogenized, flattened,
broadened, and reshaped the
world."

Parece algo inequívoco o afastamento atual a uma dita "esfera pública", supostamente de acesso generalizado, como fora conceptualizada (ou idealizada) inicialmente por Habermas (1962), que tem inclusive sido foco privilegiado de análise e discussão académica no âmbito do estudo dos média e, em 
particular, no que respeita ao género. $\mathrm{Na}$ linha de pensamento de Fraser (1990: 77), que sustenta a ideia de múltiplas esferas públicas, "... an adequate conception of the public sphere requires not merely the bracketing, but rather the elimination, of social inequality", sendo que terá de privilegiar "not the exclusion, but the inclusion, of interests and issues that bourgeois masculinist ideology labels "private" and treats as inadmissible."

A ideia de uma literacia mediática crítica, que está atenta à complexidade que permeia as transformações sociais (Lopes, 2011) e às assimetrias de poder existentes, revela-se, pois, central. $\mathrm{Na}$ nossa perspetiva, e tomando as ideias de Kellner e Share (2007), a literacia mediática crítica, ao alargar a noção base de literacia, é importante enquanto resposta educativa que, incidindo nas relações que se estabelecem entre média, públicos e poder, estimula a criação de novas mensagens desafiadoras das atuais narrativas. Paralelamente, defendemos que esta leitura crítica integre a vertente publicitária. Neste caso, a literacia crítica reflete uma conceptualização sobre o conhecimento que os públicos possuem face à publicidade (Rozendaal et al., 2011).

A nível nacional, é de notar a discussão de uma proposta de Referencial de Educação para os Média (Pereira et al., 2014), em articulação com o Ministério da Educação Português - que resultou das linhas orientadoras da investigação $-\mathrm{e}$ o desejo de aplicação prática de vários instrumentos internacionais ${ }^{4}$ nesta matéria, nomeadamente aproveitando "os recursos e oportunidades que os meios e redes de comunicação facultam para enriquecer o desenvolvimento pessoal e social, de modo a que cada pessoa possa conviver, aprender e trabalhar com mais qualidade" (Pereira et al., 2014: 5). É nesta ótica que apresentam atividades direcionadas para a publicidade e marcas e que podem ser aplicadas desde o ensino pré-escolar até ao secundário, de forma a fomentar olhares críticos nesta área mediática.

\footnotetext{
${ }^{4}$ Referimo-nos aqui especificamente às citadas pelo próprio referencial como a Diretiva 2007/65/CE, do Parlamento Europeu e do Conselho de 11 de dezembro de 2007, a Recomendação da Comissão Europeia, de 20 de agosto de 2009, a Comunicação da Comissão ao Parlamento Europeu, ao Conselho ao Comité Económico e Social Europeu e ao Comité das Regiões - Uma abordagem europeia da literacia mediática no ambiente digital, a Recomendação 1466 (2000) da Assembleia Parlamentar do Conselho da Europa e a Declaração de Grünwald sobre a Educação para os Media (UNESCO, 1982).
} 
Como referem os autores deste

Referencial,

$$
\begin{aligned}
& \text { "Ler criticamente" os media } \\
& \text { supõe ser capaz de reconhecer e } \\
& \text { valorizar aquilo que neles } \\
& \text { contribui para o alargamento de } \\
& \text { horizontes, (...) para o } \\
& \text { acolhimento da diversidade de } \\
& \text { valores e mundividências e para a } \\
& \text { construção das identidades (Idem, } \\
& \text { 2014: 6). }
\end{aligned}
$$

Segundo Zacchetti (2011: 41), a

literacia mediática remete para $\mathrm{o}$ domínio da inclusão social (à qual acrescentamos também o de intervenção), sendo fulcral no desenvolvimento de competências não apenas entre públicos mais jovens, mas também junto dos públicos em geral e dos profissionais dos média, em particular. Segundo Kellner e Share (2007), a literacia crítica mediática focaliza-se sobretudo num posicionamento ideológico e de análise de políticas de representação que incluem importantes dimensões sociais como as de género, raça, classe ou sexualidade. No que concerne a estas últimas dimensões sociais, convém destacar que estas se exacerbam no domínio da publicidade, ainda que seja um campo de investigação ainda pouco abordado nesta ótica.
A este respeito, Rozendaal e suas colaboradoras (2011) referem que a importância da literacia publicitária consiste no fomento de um posicionamento crítico, de filtro, no processamento das mensagens. Orientando-se no mesmo sentido da proposta de Kellner e Share (2007), as autoras perspetivam os públicos como elementos ativos, resistentes a leituras tendencialmente dominantes e atuantes na transformação através de leituras negociadas ${ }^{5}$. Refira-se também o trabalho desenvolvido por Reichart e colaboradoras/es (2007), que enfatiza o esforço empreendido por algumas agências publicitárias no sentido de uma maior atenção à forma como as mulheres tendem a ser representadas, assim como destaca a importância de denunciar anúncios sexistas. Por outro lado, salienta a importância da tomada de consideração ao nível das instituições de ensino, com previsível impacto na produção e na receção de imagens não sexistas.

Neste sentido, consideramos que importa dotar os públicos de ferramentas e de empowerment pessoal

\footnotetext{
5 Posicionamentos que aliás foram basilares a uma noção de literacia mediática e publicitária desde os trabalhos de Hall, 1980.
} 
que possibilitem uma efetiva leitura crítica, a qual

"... involves cultivating skills in analysing media codes and conventions, abilities to criticize stereotypes, dominant values, and ideologies, and competencies to interpret the multiple meanings and messages generated by media texts. Media literacy helps people to use media intelligently, to discriminate and evaluate media content, to critically dissect media forms, to investigate media effects and uses, and to construct alternative media (Kellner e Share, 2005: 372)."

\section{Metodologia}

A técnica de investigação utilizada para a condução desta investigação-ação correspondeu à utilização de grupos focais. Respeitando a uma técnica de pesquisa, desenvolvida por Merton e colaboradores na década de 1940 (com importante disseminação a partir de 1980), esta consubstancia-se na recolha de dados decorrente da interação social de várias/os participantes que se encontram reunidas/os em simultâneo numa entrevista, com o objectivo de discutirem um tópico sugerido pela/o entrevistador/a (Morgan, 1997).
Esta opção metodológica visou privilegiar uma metodologia de cariz qualitativo (Braun e Clarke, 2013), ainda que se reconheça que o uso desta técnica não significa uma ancoragem "à abordagem metacientífica qualitativa, pois inúmeros esforços têm sido dirigidos no sentido de ajustá-la às exigências da nomotética" (Gondim, 2003: 151). Mais do que uma qualquer rutura com abordagens de cariz quantitativo - foco particular de atenção da crítica feminista, pelo facto de representarem visões frequentemente ahistóricas e monolíticas, que assumem, inclusive, o masculino como universal (Neves e Nogueira, 2003), - a escolha prendeu-se com os objetivos gerais do projeto: conhecer, discutir, (des)construir e incentivar à ação.

Neste sentido, a realização de focus group com estudantes do ensino superior das áreas de Ciências da Comunicação, Publicidade e Marketing - enquanto futuras/os trabalhadoras/es da área e construtoras/es de discursos mediáticos $^{6}$ - visou analisar as suas

\footnotetext{
6 Tendo como base ideias aqui discutidas, com o projeto PubliDiversidade: representações sociais e igualdade de género nos media intentou-se contribuir para a promoção de competências de descodificação, desconstrução crítica e subsequentemente proatividade, tendentes à edificação de realidades pautadas pela igualdade de género. $O$ trabalho de investigação-ação que de seguida se discute incidiu
} 
percepções em matéria de igualdade de género e de diversidade em articulação com os processos de produção e receção de anúncios publicitários, bem como explorar as estratégias de (hetero e auto) regulação existentes/desejáveis nesta área. Paralelamente, e decorrente da orientação de um guião de sessão semiestruturado, procurou-se promover o debate e a desconstrução ativa e coletiva de estereótipos pelo estímulo à crítica de exemplos concretos de anúncios amplamente difundidos em revistas de estilo de vida (e.g., Benetton, Rayban, The body shop e Lee).

Assim, entre outubro de 2013 e janeiro de 2014, foram realizados 11 grupos focais, moderados pelas técnicas/investigadoras do projeto PubliDiversidade, nos quais participaram 102 estudantes das áreas de Ciências da Comunicação, Publicidade e Marketing (79 mulheres e 23 homens), entre os 19 e os 31 anos, de três universidades do norte de Portugal, entidades parceiras do projeto

sobre um público que consideramos ator em potência de transformação social nesta matéria - jovens estudantes do ensino superior das áreas de Ciências da Comunicação, Publicidade e Marketing -, não apenas pelo entendimento de que deverão integrar profissionalmente a área dos média, nomeadamente da publicidade e do marketing, mas também porque este grupo é consumidor de produtos mediáticos e parte da sociedade civil.
PubliDiversidade (tabela 1). Estes decorreram nos espaços das universidades, beneficiando a sua organização do comprometimento por parte de docentes e responsáveis pelos respetivos cursos na mobilização para a participação. 


\begin{tabular}{|l|l|l|l|}
\hline & Homens & Mulheres & Total \\
\hline Universidade Pública & 13 & 53 & 66 \\
\hline Universidade Privada (1) & 7 & 12 & 19 \\
\hline Universidade Privada (2) & 3 & 14 & 17 \\
\hline Total & 23 & 79 & 102 \\
\hline
\end{tabular}

Tabela 1: Distribuição, por sexo, das/os alunas/os das Universidade Publica e Privadas.

As sessões, com um mínimo de 8 e um máximo de 11 participantes, foram organizadas em grupos mistos, pois entendeu-se que esta configuração poderia favorecer o debate e o "contraditório". Refira-se, contudo, uma maioria expressiva de mulheres em todos os grupos, o que não deixa de ser revelador do perfil tendencialmente "feminizado" dos cursos.

Os objetivos que permearam as sessões não foram, desde logo, claramente expostos às/aos participantes. Entendeu-se que esta omissão poderia ser geradora de maior autenticidade nas participações, constrangendo a tentação de discursos "politicamente corretos". Neste sentido, e também cientes de que "o tema do género é frequentemente descartado e mal recebido nestes debates, chegando mesmo a provocar perda de interesse entre os participantes" (Lobo e Cabecinhas, 2013:209), as sessões tiveram início com um conjunto de questões mais gerais e relativas à publicidade, suas formas e veículos privilegiados de disseminação, bem como constrangimentos de ordem interna e externa, sendo as/os participantes ainda convidadas/os a enunciarem e justificarem exemplos de bons e maus anúncios publicitários.

Dos dados obtidos, após a transcrição (seleção e revisão), procedeuse a uma análise de conteúdo. Os grupos focais haviam sido gravados em formato audiovisual (tendo sido preenchido pelas/os participantes um consentimento informado), de forma a facilitar a análise. De forma a preservar o anonimato, os nomes que constam das citações das/os participantes são fictícios.

\section{Análise e Discussão}

Os grupos focais revelaram-se relativamente heterogéneos, não fossem as dinâmicas próprias da interação em cada um deles e, previsivelmente, devido aos perfis dos cursos de origem das/os 
participantes (da comunicação ou da publicidade, mais ou menos orientados por uma visão de mercado). Embora se tenha verificado uma escassez de visões amplamente críticas, o diálogo entre as/os participantes potenciou a emergência de discursos (re)ativos e denunciadores de alguma reflexividade, nomeadamente no que respeita às questões de género na publicidade.

Em termos de resultados podemos referir que, no âmbito da discussão em grupo, o tópico do género e diversidade foi raramente suscitado. Porém, é de relevar, por exemplo, a menção de campanhas dirigidas à prevenção da violência doméstica como ilustrativas de impacto ao nível dos públicos e, pela negativa, campanhas publicitárias de seguradoras pelo facto de veicularem liminarmente estereótipos sexistas. Para esse facto, aponta a seguinte citação:

"Anúncios que são sexistas são muito mal feitos. Ainda agora, em casa, estava a ver um [com] uma mulher no cabeleireiro e em que um pintor lhe pintou o cabelo de cor-derosa. Ela diz: 'mas eu tenho seguro'. É estúpido!” (Raquel, 19 anos, GF2).

É de destacar que os anúncios televisivos promovidos por seguradoras foram, aliás, referenciados com alguma frequência como paradigmáticos da presença de estereótipos de género, uma vez que à época das sessões estas campanhas publicitárias marcavam com maior presença o primetime da televisão portuguesa e abordavam especificamente as questões de género (e.g., Seguro OK Mulher).

\section{Estereótipos na publicidade: uma}

\section{estratégia de adequação aos públicos?}

Quando questionadas/os sobre a presença de mulheres e de homens na publicidade, esta foi apontada pela maioria das/os participantes como sendo numericamente equitativa. No entanto, já desde os anos 1990 que se perspetiva que essa participação não corresponde a uma equiparação nos papéis de género representados na publicidade (Davis, 1990). A dificuldade em verificar esta distinção, e mesmo uma pequena superioridade de imagens femininas (Magalhães, 2014), reflete as (in)visibilidades de "diversas experiências e papéis de género assumidos por mulheres e homens [que] parecem continuar silenciados ou secundarizados, e, por outro [lado], a visibilidade que é dada a determinadas realidades continua a ser pouco diversificada e por isso extremamente redutora (Arnaut, 2011)" (Cerqueira, 2014: 8). Neste sentido, esta 
percepção de que a representação quantitativa entre mulheres e homens é igual poderá ser reveladora da incorporação de estereótipos de género pelas/os participantes, como ilustram as passagens que se seguem:

"Eu acho que são as mulheres, realmente. Vejo mais mulheres protagonistas na publicidade porque se calhar as mulheres são mais [consumistas]" (Paula, 19 anos (GF7).

"E gostam de ir às compras (...) Os homens não é (...) por verem mais TV ou assim. As mulheres veem novelas, $\log 0$ veem os intervalos e logo veem a publicidade. Estão em casa, têm a TV ligada, mesmo que não estejam a ver (...) podem estar a ouvir. Também são as que têm mais contacto com publicidade" (Bárbara, 19 anos, GF7).

"Se o produto tem um consumo de $80 \%$ de mulheres e $20 \%$ de homens (...), não vais tentar vender aos homens" (Hugo, 20 anos, GF9).

Estas citações demonstram, pois, a ideia de consumo associado tendencialmente às mulheres, com impacto nos produtos publicitários, bem como a existência de um olhar claramente parcelar sobre a realidade multifacetada vivenciada por estas no contexto atual, acentuandolhes o vínculo ao domínio do privado. Por outro lado, a frequência com que as

mulheres surgem em anúncios publicitários a produtos cujos destinatários atribuídos são homens (e.g., cerveja e automóveis) raramente foi questionada pelas/os participantes.

Contudo, mais do que a tónica na representação quantitativa, surgiu espontaneamente nos vários grupos focais a ideia de que a forma como as mulheres e os homens aparecem nas imagens publicitárias e os papéis sociais que lhes são associados (em articulação com os produtos anunciados) são distintos. A este propósito, importa notar a existência de um conjunto de discursos críticos e de resistência:

"Tens produtos específicos para mulher, agora quando é assim um produto geral, não é? Podiam criar qualquer coisa diferente. Utilizam a mulher como um objecto só mesmo para embelezar e as pessoas vão ver aquele anúncio simplesmente porque está ali uma mulher de calçõezinhos curtos, com alto decote" (Sofia, 19 anos, GF8).

"A mulher é sempre o objecto de atração. O homem pode ser o objecto de atração mas também, às vezes, é glorificado na publicidade: é o herói, a estrela" (Elsa, 20 anos, GF9).

As visões enunciadas revelam-se particularmente críticas em relação aos papéis desempenhados por mulheres e 
homens nos anúncios publicitários, considerando que as primeiras tendem a ser alvo de objetificação/sexualização e os segundos frequentemente enaltecidos (Veríssimo, 2005). Todavia, foi também realçada - ainda que com pouca frequência - a circunscrição e a inadequação de estereótipos relativos à masculinidade (Januário, 2016). Como refere um participante:

\begin{abstract}
"Mas será que (...) a publicidade não continua a ver o homem como algo muito redutor? Ou seja, (...) o homem ou bebe cerveja (risos) ou é (...) metro (risos). Acho que em termos de público, a publicidade reduz mais facilmente o homem. É aquela coisa do 'homem é todo igual'. (...) Eu acho que é também pelo facto das mulheres serem mais versáteis, têm mais opções de escolha, mais... a sério! A nível de cabelo, de cor, de roupas..." (Rui, 21 anos, GF8).
\end{abstract}

A passagem anterior ilustra a ideia de que a publicidade é avessa à diversidade no que toca ao 'ser mulher' $\mathrm{e}$ ao 'ser homem', sugerindo que este facto se ancora numa realidade comercial que reduz o leque de possibilidades e se centra numa imagem percebida do modo como mulheres e homens se comportam ou deviam comportar-se (Gornick, 1979 cit in Baker, 2005). A articulação entre o que é veiculado pela publicidade comercial e os públicos foram enunciados, ademais, ao longo das diversas sessões, como um constrangimento (entendido, em grande parte dos casos, como inabalável) à disseminação de conteúdos assentes nos princípios da igualdade de género. Este aspeto fica evidenciado na seguinte passagem:

"Se aquilo é um anúncio comercial, se é para a maior parte das pessoas, se para o senso comum é a mulher que limpa, tem de ser assim o anúncio. (...) Não vão meter um homem a limpar" (Vera, 19 anos, GF3).

No entanto, a perspetiva (maioritária) de que a publicidade não pode, nem deve, pelo seu vínculo ao mercado, comportar ideias que desafiem assimetrias sociais e estereótipos de género não se configurou exclusiva. Os trechos que se seguem, os quais remetem para o diálogo entre dois participantes, permitem exemplificar tensões acerca do potencial da publicidade para a mudança social.

"Eu acho que (..) a sociedade continua ainda muito machista, apesar de a gente ter evoluído muito. Mas eu acho que a publicidade continua mais machista ainda que a sociedade ..., sabe? (...) Podia mudar muito a visão [e] até ajudar a 
sociedade a evoluir" (Catarina, 20 anos, GF10).

"Eu discordo porque é básico. (...) Se eu já sei que o público vai aceitar esta publicidade, não é? Para que é que eu vou estar a arriscar? (...) Olha! Tão simples quanto isto: se a sociedade não aceita a homossexualidade, para que é que eu vou arriscar o nome da minha empresa a criar uma campanha unicamente para os homossexuais?" (Vitor, 20, GF10).

"É isso... A sociedade não aceita a homossexualidade, tem de aceitar, entendeu?" (Catarina, 20 anos, GF10).

Enquanto o discurso da primeira participante ressalta a necessidade de um maior compromisso social da publicidade com a mudança de mentalidades e a disseminação de conteúdos não sexistas/heteronormativos, o segundo participante apresenta uma lógica essencialmente mercantilista e redutora da complexidade que permeia os atuais contextos socioculturais (Martins, 2016). Porém, ainda em articulação com uma perspetiva de mercado, emergiu em alguns grupos a percepção de que se a publicidade não responde apenas a necessidades, tendo também um papel determinante na sua criação, esta deveria estar mais aberta à diversidade, com impacto no surgimento de novos públicos/consumidoras/es. Como refere uma participante:

"Isso é como (...) os videojogos, (...) os anúncios do FIFA ou do PES.

Sei bem que são estrelas de futebol, mas também há estrelas de futebol feminino que quase ninguém conhece e se calhar (...) acabavam por chamar muito mais atenção para o desporto" (Inês, 20 anos, GF9).

$\mathrm{Na}$ mesma linha, foi sublinhado também o facto de os anúncios publicitários poderem desafiar as normas sociais, causar "choque", levar à discussão e à reflexão e, consequentemente à disseminação da mensagem, ampliando o potencial de consumo (e.g. Arnaut, 2011; Martins, 2016). Nas palavras de uma participante:

"Voltando à parte da homossexualidade (...), eu acho que mesmo não estando (...) o país preparado para visualizar ou aceitar (...) acho que, mesmo assim, eles deveriam ser publicitados. (...) vai gerar polémica e [resultar]" (Susana, 20 anos, GF9).

Se é evocada, em maior ou menor grau, a necessidade de articulação da publicidade com a percepcionada "realidade" dos públicos, alguns discursos remontaram para a capacidade de as/os consumidoras/es selecionarem e relativizarem as mensagens estereotipadas veiculadas: 
“(..) está mais ou menos estereotipado que toda a gente pensa não sei quê ou pensava. (...) nós mulheres que já não somos só para estar em casa a limpar e o homem é que trabalha... vemos uma publicidade assim [e] não estranhamos. (...) Levamos a bem porque achamos que é engraçado mostrar a outra faceta que nós já tivemos. Já não vamos ficar ofendidas, não é? Porque às vezes eu acho que nós conseguimos interpretar as coisas de outra maneira (Helena, 19 anos, GF1).

Não negando que os significados que podem decorrer dos processos de interpretação dos conteúdos publicitários serão múltiplos, a perspetiva enunciada revela-se parcelar ou mesmo unilateral. Por um lado, presume-se que a maioria das mulheres se afasta da realidade que é transmitida e, por outro lado, que é dotada de instrumentos para a questionar ou mesmo ridicularizar. $\mathrm{O}$ trecho que se segue caminha também neste sentido:

"Eu acho que às pessoas ditas normais, a diversidade na Publicidade não faz diferença. Mas para as pessoas que não se sentem totalmente enquadradas na sociedade faz..." (Cláudia, 19 anos, GF2).

Foi possível verificar alguns momentos de consenso nos vários grupos focais no que concerne ao impacto da imagem corporal das/os protagonistas em anúncios publicitários na auto-imagem e nos comportamentos individuais (de consumo, alimentares, etc.). $\mathrm{Na}$ maioria dos casos, foi referido que os padrões (ocidentais) de beleza - em particular, aqueles que são aplicados às mulheres e estão associados a ideais de perfeição, jovialidade e magreza - tendem a constituir um problema, na medida em que não se traduzem (nem se traduzirão) na realidade, gerando insatisfação e preconceitos (c.f Magalhães 2011, 2016). Porém, o reconhecimento do problema não tornou visíveis discursos de particular rutura, tendo sido reiterada, inclusive, a presença de uma heteronormatividade considerada compulsória (e.g. Louro, 2003). Atentemos ao seguinte diálogo:

"As mulheres querem ser magras porque a sociedade impõe que (...) uma mulher bonita é magra. Ponto. Mas eu quero ser magra por mim...” (Andreia, 20 anos, GF10).

"Tu queres ser magra porque se fores gorda muito dificilmente... E peço desculpa porque está a soar a machismo, mas muito dificilmente vais ter tantos rapazes quanto isso interessados em ti. Tu queres ser magra por questões de saúde ou algo do género, ou porque as tuas amigas dizem que estás muito gorda ou porque sais à noite e ninguém olha 
para ti. Pá...é verdade! É verdade!” (Vitor, 20 anos, GF10).

Ficam evidenciadas neste trecho as tensões existentes no seio da sociedade (Magalhães, 2011, 2016) em relação aos ideais de beleza (normativa), sendo que a publicidade - participando na (re)produção daqueles - desempenha aqui um papel importante. Enquanto os discursos de rutura com a norma foram escassos, os posicionamentos consonantes com a ideia da publicidade como produtora de sonhos (isto é, incompatível com imagens excessivamente "realistas") emergiram com alguma frequência. A este propósito, uma participante refere:

“... ao mostrar a perfeição (...) todo o ser humano quer. Não digo que quer ser perfeito, mas quanto melhor, ainda melhor. Então, essas publicidades que mostram a realidade, umas mostram a realidade demasiado real e feia (...). Outros fazem-na demasiado perfeita de modo a fazer com que pessoa fique conquistada" (Rita, 19 anos, GF7).

Após a discussão em torno do género e diversidade, inclusive mediante a apresentação de um conjunto de imagens como material de estímulo, as/os participantes foram questionadas/os relativamente a experiências de denúncia de anúncios publicitários e suas correlativas motivações. Foram relatadas, de forma residual, situações em que este procedimento tivesse ocorrido, mas nenhuma delas remeteu para situações de sexismo. Um participante afirmou:

"Em termos de publicidade, sou extremamente liberal. Não me importo com estereótipos. Não me importo que façam coisas mal porque o conceito é vender" (Ricardo, 18 anos, GF3).

Não expressando com exatidão o grosso das opiniões transmitidas pelas/os participantes, que se revelaram tendencialmente mais moderadas, esta citação acaba por revelar o alheamento face a qualquer tipo de regulação de conteúdos publicitários, não fosse $\mathrm{o}$ pendor mercantilista dos mesmos. Ademais, foi frequentemente invocado o domínio das escolhas pessoais, em termos de consumo, como estratégia de penalização em relação a anúncios considerados inadequados. Referindo-se a um anúncio sexista de uma seguradora, uma participante afirmou:

"Assim, no máximo, eu posso dizer que (...) foi essa dos seguros. E se tivesse que fazer um seguro, fazia em todo o lado menos naquela empresa" (Helena, 20 anos, GF3).

Este excerto não traduz, de modo algum, o padrão de respostas, pois o género raramente foi referenciado a este 
nível. Neste sentido, os anúncios publicitários objeto de denúncia corresponderam, essencialmente, aos que remetem para o âmbito da concorrência desleal (por exemplo, a referência a marcas concorrentes) ou veiculam publicidade enganosa, atendendo à qualidade/propriedades dos produtos, remetendo mais uma vez para o nãoreconhecimento ou invisibilidade da importância de questões como o sexismo e as violências de género. As próprias estratégias de denúncia revelaram-se, inclusivamente, afastadas de contextos institucionais. Embora fosse realçado o papel de organismos como a Associação Portuguesa para a Defesa do Consumidor (DECO) e, com menor frequência, a Entidade Reguladora para a Comunicação Social (ERC), o veículo considerado como fundamental na atuação sobre denúncias foi a internet, nomeadamente as redes sociais. Um participante referiu:

\footnotetext{
"A internet veio dar uma liberdade ao consumidor que nunca antes se viu (...). O público geral chegava a um jornal e dizia 'comprei esta garrafa de água e não prestava'. Agora todos temos a liberdade de poder chegar a uma rede social, seja o twitter, seja facebook, que têm a capacidade de tornar coisas virais, o que é fascinante" (Paulo, 21 anos, GF 8).
}

Mediante a simples partilha de informação/opinião entre pares ou assumindo o formato de queixa na página das próprias empresas, ferramentas como o facebook foram entendidas pelas/os participantes como a forma, por excelência, de contestação de anúncios publicitários. Neste sentido, a verificação desta desvalorização de estratégias de intervenção/denúncia de conteúdos publicitários sexistas e discriminatórios acaba por não surpreender ao se articular com a crença partilhada de que a publicidade traduz a relativa homogeneidade dos contextos sociais dos quais emerge.

\section{Considerações finais}

Neste artigo discutiram-se as percepções de jovens estudantes relativamente às representações de género na publicidade e correlativos processos e estratégias de (hetero e auto)regulação existentes, tendo por base a realização de grupos focais que procuraram promover 0 debate e a desconstrução crítica com as/os participantes de forma a potencializar condutas ativas em favor da igualdade de género.

No estudo realizado, verificou-se o reconhecimento generalizado entre as/os participantes de que a publicidade é 
perpassada por representações estereotipadas relativamente ao género. É reconhecida a utilização de estereótipos de género na publicidade, uma vez que estes permitem criar uma familiaridade enquanto reprodutores de determinadas realidades sociais (Soley \& Craig, 1992). Todavia, a maioria dos discursos reproduzidos pelas/os jovens, longe de consubstanciar perspetivas críticas e de rutura, foi frequentemente ancorada no vínculo entre a publicidade e os contextos socioculturais e económicos da sua produção. Este facto redundou, muitas vezes, num entendimento da publicidade enquanto subsidiária da sociedade, numa acepção essencialmente mercantilista. Não se evidenciaram, por conseguinte, também práticas ativas de denúncia e de intervenção em relação a conteúdos de pendor sexista, remetendo-se a sua condenação para o domínio das escolhas privadas de consumo.

Atendendo aos resultados acima descritos, considera-se de extrema relevância a promoção de projetos e ações no sentido da desconstrução ativa de conteúdos publicitários, de ações de sensibilização e (in)formação junto de (futuros/as) profissionais da área da comunicação, bem como o desenvolvimento de estratégias concertadas com vista à promoção da igualdade de género na sociedade civil e junto das instâncias políticas. Além disso, importa investir na investigação científica sobre a utilização dos média digitais, nomeadamente as redes sociais, enquanto espaços que permitem a discussão (crítica) sobre as representações de género e a emergência de contra-discursos publicitários.

\section{Nota de agradecimentos}

As autoras gostariam de agradecer os contributos das/os alunas/os que se voluntariaram para os grupos focais, bem como às/aos professoras/es e instituições de pertença, que favoreceram a sua realização, nomeadamente o Instituto de Ciências Sociais da Universidade do Minho, o Departamento de Ciências da Comunicação da Universidade Fernando Pessoa e o Departamento de Ciências da Comunicação e da Cultura da Universidade Lusófona do Porto.

\section{Financiamento}

Este trabalho foi apoiado financeiramente pelo consórcio estabelecido entre o Fundo Social Europeu e o Programa Operacional para o Potencial Humano, no âmbito do Quadro de Referencia de Estratégia Nacional ao 
abrigo da gestão da Comissão para a Cidadania e Igualdade de Género (FSE/POPH/QREN/CIG $\mathrm{n}^{\circ}$ 086347/2012/73).

\section{Referências Bibliográficas}

Almeida, João Ferreira de (2013), Desigualdades e perspetivas dos cidadãos. Portugal e a Europa. Lisboa: Editora Mundos Sociais.

Amâncio, Lígia (1994), Masculino e feminino: construção social da diferença. Porto: Edições Afrontamento.

Arnaut, Catarina (2011), As questões de Género na Publicidade: percepções de estudantes e profissionais das área do Marketing e da Publicidade [Dissertação de Mestrado não publicada]. Gestão de Serviços, Faculdade de Economia, Universidade do Porto, Porto, Portugal.

Baker, Christina N. (2005), "Images of Women's Sexuality in Advertisements: A content analysis of Black- and WhiteOriented Women's and Men's Magazines", Sex Roles, 52(1/2), 13-27.

Betterton, Rosemary (1987), "Introduction: Feminism, Femininity and Representation", in Rosemary Betterton
(Ed.), Looking on, Images of Femininity in the Visual Arts and the Media. London: Pandora, 1-17.

Braun, Virginia; Clarke, Vitoria (2013), Successful qualitative research: A practical guide for beginners. Los Angeles|London|New

Delhi|Singapore|Washington, DC: Sage Publications.

Cabecinhas, Rosa (2007), Preto e Branco. A naturalização da discriminação racial. Porto: Campo das Letras.

Cerqueira, Carla \& Cabecinhas, Rosa (2012). 'Políticas para a igualdade entre homens e mulheres nos media: da (inov)ação legislativa à mudança social'. Ex Aequo, 25: 105-118.

Cerqueira, Carla (2012), Quando elas (não) são notícia: mudanças, persistências e reconfigurações na cobertura jornalística sobre o Dia Internacional da Mulher em Portugal (1975-2007) [Tese de Doutoramento não publicada]. Ciências da Comunicação, Instituto de Ciências Sociais, Universidade do Minho, Braga, Portugal. 
Cerqueira, Carla (2014), "Os média, os públicos e os discursos de género: (in)visibilidades, linguagens e protagonistas", in, Ana M. Jorge, Carla Cerqueira \& Sara I. Magalhães (Eds), PubliDiversidade. Representações Sociais e Igualdade de Género na Publicidade. Braga: UMAR, 7-16.

CIDM (2005), Estratégias Internacionais para a Igualdade de Género: a Plataforma de acção de Pequim (1995-2005). Lisboa: Comissão para a Igualdade e para os Direitos das Mulheres.

Creedon, Pamela \& Cramer, Judith (2007), Women in Mass Communication. Cresskill, Nova Iorque: Hampton Press. Crenshaw, Kimberlé (2002), "Documento para o encontro de especialistas em aspectos da discriminação racial relativos ao género", Estudos feministas, 1, 171189.

Cronin, Anne (2000), Advertising and Consumer Citizenship. London: Routledge.

Davis, Simon (1990), "Men as Success Objects and Women as Sex Objects: A Study of Personal Advertisements", Sex Roles 23(1/2), 43-50.
Esteves, João Pissarra (2003), Espaço público e democracia. Lisboa: Edições Colibri.

Faludi, Susan (1991), Backlash. The Undeclared War Against Women. Nova Iorque: Crown Publishers.

Fraser, Nancy (1990), "Rethinking the Public Sphere: A Contribution to the Critique of Actually Existing Democracy", Social Text, 25/26, 56-80.

Gallagher, Margaret (1995), “O imperialismo de baton e a nova ordem mundial: as mulheres e os media no fim do séc. XX”, in Maria João Silveirinha (Ed.), As mulheres e os Media. Lisboa: Livros Horizonte, 69-96.

Gallagher, Margaret (2001), Gender Setting. News agenda for media monitoring and democracy. London: Zed Press.

Gallego, Juana (2013), De reinas a ciudadanas: motor o rémora para la igualdad. España: Aresta.

Goffman, Erving (1979), Gender advertisements. Cambridge: Harvard University Press. 
Gondim, Sônia (2003), “Grupos Focais como técnica de investigação qualitativa: desafios metodológicos”, Paidéia, 12(24), 149-161.

González, Martin et al. (1991), La publicidade, desde el consumidor. Bizkaia: Eroski.

Habermas, Jürgen (1962, trans. 1989), The Structural Transformation of the Public Sphere: An Inquiry into a category of Bourgeois Society. Cambridge: Polity Press.

Hall, Stuart (1980), "Encoding/Decoding”. In Stuart Hall, Dorothy Hobson, Andrew Lowe \& Paul Willis (Eds.), Culture, media, language. London: Hutchinson, 128-138.

Hall, Stuart (1997), "The work of representation", in Stuart Hall (org.), Representation. Cultural representation and cultural signifying practices. London/Thousand Oaks/New Delhi: Sage/Open University, 1-74.

Januário, Soraia (2016), Masculinidades em (Re)Construção. Gênero, Corpo e Publicidade. Covilhã, Labcom.
Januário, Soraia; Cascais, António Fernando (2012), “O corpo masculino na Publicidade: uma discussão contemporânea", Comunicação e Sociedade, 21, 135 - 148.

Jodelet, Denise (1989), "Les représentations sociales : un domaine en explanation", in Denise Jodelet (eds.) Les representations sociales. Paris: PUF, 4778.

Kellner, Douglas; Share, Jeff (2005), "Toward Critical Media Literacy: Core concepts, debates, organizations, and policy". Discourse: studies in the cultural politics of education, 26(3), 369_386

Kellner, Douglas; Share, Jeff (2007), "Critical media literacy is not an option", Learning Inquiry, 1(1), 59-69.

Killbourne, Jean (1999), Deadly Persuasion: Why Women and Girls Must Fight the Addictive Power of Advertising. New York: Free Press.

Lazar, Michelle (2014), "Recuperating feminism, reclaiming femininity: hybrid postfeminist I-dentity in consumer advertisements". Gender \& Language, 8(2), 205-224. 
Lobo, Paula \& Cabecinhas, Rosa (2013), "Perspetivas de género no acesso ao espaço público mediatizado: refletindo sobre os conteúdos noticiosos do telejornal", Estudos em Comunicação, 13, 195-236.

Lopes, Paula (2011), "Literacia(s) e literacia mediática”. CIES e-Working Paper N. 110/2011. Consultado a 18.11.2016, em: http://www.cies.iscte.pt/destaques/docume nts/CIES-WP110_Lopes.pdf

Lorenzi-Cioldi, Fabio (2002), Les représentations des groupes dominants et dominés. Collections et agrégats. Grenoble: Presses Universitaires de Grenoble.

Louro, Guacira (2003), "Corpos que escapam". Estudos feministas. Consultado a 18.11.2016, em: http://www.pibid.ufpr.br/pibid_new/uploa ds/edfisica2011/arquivo/243/corpos_que_e scapam.pdf

Lippman, Walter (1922), Public opinion. Nova Iorque: MacMillan.

Machado, Helena; Santos, Filipe (2009), "A moral da justiça e a moral dos media:

Julgamentos mediáticos e dramas públicos". Oficina do CES, 333, 1-18. Consultado a 17.11.2015, em: http://www.ces.uc.pt/publicacoes/oficina/fi cheiros/333.pdf.

Magalhães, Sara I. (2016), Como ser uma Ragazza. Discursos de sexualidade numa revista para raparigas adolescentes. Saarbrücken: NEA - Novas Edições Acadêmicas.

Magalhães, Sara I. (2014), “Análise de anúncios publicitários em revistas estilo de vida portuguesas - um estudo de caso", in, Ana M. Jorge, Carla Cerqueira \& Sara I. Magalhães (Eds), PubliDiversidade. Representações Sociais e Igualdade de Género na Publicidade. Braga: UMAR, 17-33.

Magalhães, Sara I. (2011), Como ser uma Ragazza. Discursos de sexualidade numa revista para raparigas adolescente. [Tese de Doutoramento não publicada], Psicologia da Educação, Escola de Psicologia, Universidade do Minho, Braga, Portugal.

Marshment, Margaret (1993), "The Picture is Political: Representation of Women in Contemporary Popular Culture", in Diane 
Richardson \& Victoria Robinson (Eds.), Introducing Women's Studies. London: Macmillan Press, 123-150.

Martins, Mafalda S. (2016), A representação do corpo feminine na publicidade: um estudo de caso na revista ACTIVA. [Relatório de Estágio não publicado], Comunicação e Jornalismo, Faculdade de Letras, Universidade de Coimbra, Coimbra, Portugal.

Morgan, David (1997), Focus group as qualitative research. Qualitative Research Methods Series. London: Sage Publications.

Moscovici, Serge (1981), "Social Representations, Social Cognition", in Joseph Forgas (ed.), Social CognitionPerspectives on everyday understanding. Londres: Academic Press, 181-209.

Mota Ribeiro, Silvana (2010), Do outro lado do espelho: imagens e discursos de género nos anúncios das revistas femininas, uma abordagem sociosemiótica visual feminista. [Tese de Doutoramento não publicada]. Ciências da Comunicação, Instituto de Ciências Sociais, Universidade do Minho, Braga, Portugal.
Neves, Sofia; Nogueira, Conceição. (2003). "A psicologia feminista e a violência contra as mulheres na intimidade: a (re)construção dos espaços terapêuticos", Psicologia $\&$ Sociedade 15(2), 43 - 64.

Pereira, Sara et al. (2014), Referencial de Educação para os Media para a Educação Pré-escolar, o Ensino Básico e o Ensino Secundário. Lisboa: Ministério da Educação e Ciência.

Rasquilha, Luís (2009), Publicidade. Lisboa: Gestão Plus.

Reichert, Tom et al. (2007), “A Test of Media Literacy Effects and Sexual Objectification in Advertising", Journal of Current Issues an Research in Advertising, 29(1), 81-92.

Ross, Karen (2009), Gendered Media: Women, Men, and Identity Politics: Maryland: Rowman \& Littlefield Publishers.

Rozendaal, Esther et al. (2011), "Reconsidering Advertising Literacy as a Defense Against Advertising Effects", Media Psychology, 14(4), 333-354.

Soley, Lawrence; Craig, Robert (1992), "Advertising Pressures on Newspapers: A 
Survey", Journal of Advertising, 21(4), 110.

Silva, Manuel Carlos (2008), "Desigualidades de género". Configurações, 4, 65-89.

Subtil, Filipa (2009), 'Anotações sobre o processo de feminização da profissão de jornalista na década de 1990' in Garcia, José Luís (org.) Estudos sobre os jornalistas portugueses: metamorfoses e encruzilhadas no limiar do século XXI. Lisboa: Imprensa de Ciências Sociais: 93108.

Tajfel, Henri (1982), Social Identity and Intergroup Relations. Cambridge:

Cambridge University Press.

Thomas, Elizabeth; Jolls, Tessa. (2004), "Media Literacy - A National Priority for a Changing World", American Behavioral Scientist, 48(1), 18-29.

Thornham, Susan (1998), 'Feminist Media and Film Theory' in Jackson, Steve \& Jones, Jackie (eds.) Contemporary Feminist Theories. Edimburgo: Edinburgh University Press.
Tuchman, Gaye (1979), "Introduction: the symbolic annihilation of women by mass media", in Gaye Tuchman et al. (Org.), Hearth and Home: Images of Women in the Mass Media. New York: Oxford University Press, 3-38.

Van Dijk, Teun (1991), Racism and the Press. Nova Iorque: Routledge.

Van Zoonen, Lisbeth (1994), Feminist Media studies. Newbury Park, CA: SAGE. Veríssimo, Jorge (2005), "A mulher "objecto" na publicidade", Livro de actas do IV Congresso SOPCOM - Repensar os media: novos contextos da comunicação e da informação. Aveiro: Universidade de Aveiro, 1701-1721.

Zacchetti, Matteo (2011), "Literacia mediática: uma abordagem europeia", comunicação apresentada no Congresso Literacia, Media e Cidadania, Braga.

Zawisza, Magdalena; Cinnirella, Marco (2010), "What Matters More Breaking Tradition or Stereotype Content? Envious and Paternalistic Gender Stereotypes and Advertising Effectiveness", Journal of Applied Social Psychology, 40(7), 1767-1797. 